\title{
Genomics-based Sensitive and Specific Novel Primers for Simultaneous Detection of Burkholderia glumae and Burkholderia gladioli in Rice Seeds
}

\author{
Chaeyeong Lee ${ }^{\dagger}$, Hyun-Hee Lee ${ }^{\dagger}$, Mohamed Mannaa ${ }^{\dagger}$, Namgyu Kim, Jungwook Park, Juyun Kim, and \\ Young-Su Seo (1D)* \\ Department of Microbiology, Pusan National University, Busan 46241, Korea
}

(Received on 26 July, 2018; Revised on 25 August, 2018; Accepted on 28 August, 2018)

Panicle blight and seed rot disease caused mainly by Burkholderia glumae and Burkholderia gladioli is threatening rice cultivation worldwide. The bacteria have been reported as seed-borne pathogens from rice. Accurate detection of both pathogens on the seeds is very important for limiting the disease dissemination. Novel primer pairs targeting specific molecular markers were developed for the robust detection of $\boldsymbol{B}$. $g l u$ $m a e$ and $B$. gladioli. The designed primers were specific in detecting the target species with no apparent crossreactions with other related Burkholderia species at the expected product size. Both primer pairs displayed a high degree of sensitivity for detection of $B$. glumae and $B$. gladioli separately in monoplex PCR or simultaneously in duplex PCR from both extracted gDNA and directly preheated bacterial cell suspensions. Limit of detection was as low as $0.1 \mathrm{ng}$ of gDNA of both species and $3.86 \times 10^{2}$ cells for $B$. glumae and $5.85 \times 10^{2}$ cells for $B$. gladioli. On inoculated rice seeds, the designed primers could separately or simultaneously detect $B$. glumae and $B$. gladioli with a detection limit as low as $1.86 \times 10^{3}$ cells per rice seed for $B$. glumae and $1.04 \times 10^{4}$ cells per rice seed of $B$. gladioli. The novel primers maybe valuable as a more sensitive, specific, and robust tool for

\footnotetext{
${ }^{\dagger}$ These authors contributed equally to this work.

*Corresponding author.

Phone) +82-51-510-2267, FAX) +82-51-514-1778

E-mail)yseo2011@pusan.ac.kr

ORCID

Young-Su Seo

http://orcid.org/0000-0001-9191-1405

(c) This is an Open Access article distributed under the terms of the Creative Commons Attribution Non-Commercial License (http:// creativecommons.org/licenses/by-nc/4.0) which permits unrestricted noncommercial use, distribution, and reproduction in any medium, provided the original work is properly cited.
}

Articles can be freely viewed online at www.ppjonline.org. the efficient simultaneous detection of $B$. glumae and $B$. gladioli on rice seeds, which is important in combating rice panicle blight and seed rot by early detection and confirmation of the dissemination of pathogen-free rice seeds.

Keywords : Burkholderia gladioli, Burkholderia glumae, dual detection, PCR

Handling Associate Editor : Sohn, Kee Hoon

Rice (Oryza sativa L.) is among the most important cereal food crops, providing up to $50 \%$ of the total consumed human dietary calories (Awika, 2011). The growing human population and related increasing food demand are demanding the continuous enhancement of food production and minimization of crop losses by limiting devastating plant diseases (FAO, 2009).

Bacterial grain rot and panicle blight is caused mainly by bacteria, such as Burkholderia glumae and B. gladioli. The disease threatens rice cultivation, with up to $75 \%$ of the drop being lost in heavily infected fields (Ham et al., 2011). The disease was originally identified in Japan, where seedling blight and grain rot were caused by $B$. glumae on rice (Goto and Ohata, 1956). B. glumae can cooperatively interact with the air-borne fungal pathogen, Fusarium graminearum, on rice grains, leading to potentially huge losses in crop yield (Jung et al., 2018). B. gladioli can also produce similar symptoms of panicle blight and seed rot on rice. The disease has spread to other rice-growing regions including other East-Asian countries, the United States, and South America (Cottyn 1996; Jeong et al., 2003; Nandakumar et al., 2009). Several symptoms are associated with infections of $B$. glumae and B. gladioli on rice seedlings and on grains, including aborted kernels, unfilled grains, and discoloration (Trung et al., 1993; Ura et al., 2006). 
Both B. glumae and B. gladioli are considered seedborne pathogens, as both were isolated from rice seeds and their seed-borne nature was confirmed in several previous reports (Cottyn et al., 2001; Nandakumar et al., 2008; Ura et al., 2006). B. glumae was also detected in various parts (e.g., epidermis and parenchyma) of naturally infected seeds (Hikichi et al., 1993). In one study, seven B. glumae and six $B$. gladioli strains were isolated from symptomatic rice leaf sheath and seeds, and all were pathogenic to rice (Ura et al., 2006). The seed-borne nature of these pathogens could allow their widespread distribution (Cottyn et al., 2009). Early and accurate detection of B. glumae and $B$. gladioli on rice seeds are important for epidemiological studies and to provide pathogen-free seeds, which could limit the spread and reduce the incidence of disease (Ham et al., 2011). Morphological, biochemical, and serological detection methods for $B$. glumae and $B$. gladioli have been explored, and conventional methods, including selective and semi-selective media combined with morphological characterization, developed. Tsushima et al. (1986) developed a selective medium designated S-PG. More recently, the more selective CCNT and SMART media were developed (Kawanishi et al., 2011; Kawaradani et al., 2000). These methods rely on the culture and morphological characterization of colonies. The approach is time-consuming and requires other reliable serological and molecular confirmations for accurate diagnosis.

Molecular detection and identification using the polymerase chain reaction (PCR) is an efficient and sensitive method for detection of low numbers of bacterial pathogens (Maeda et al., 2006; Takeuchi et al., 1997). Generally, the molecular detection of bacterial pathogens relies on the amplification and sequencing of 16S rRNA gene sequences (Furuya et al., 2002; Stackebrandt and Goebel, 1994). However, in some cases, 16S rRNA gene sequence analysis is insufficient to discriminate between closely related species, such as $B$. glumae and B. gladioli (Maeda et al., 2006; Salles et al., 2002). The slow rate of evolution

Table 1. List of bacterial strains or genomic DNA used in this study

\begin{tabular}{|c|c|c|}
\hline Strain & Origin & Reference or source \\
\hline \multicolumn{3}{|l|}{ Burkholderia glumae } \\
\hline BGR1 & South Korea & (Jeong et al., 2003) \\
\hline $411 \mathrm{gr}-6$ & USA & (Nandakumar et al., 2009) \\
\hline 201 sh-1 & USA & (Nandakumar et al., 2009) \\
\hline $957856-41-\mathrm{c}$ & USA & (Nandakumar et al., 2009) \\
\hline $117 \mathrm{~g} 1-7-\mathrm{a}$ & USA & (Nandakumar et al., 2009) \\
\hline \multicolumn{3}{|l|}{ Burkholderia gladioli } \\
\hline BSR3 & South Korea & (Seo et al., 2011) \\
\hline KACC 18962 & South Korea & NAS \\
\hline KACC 18963 & South Korea & NAS \\
\hline KACC 13944 & South Korea & (Lee et al., 2010) \\
\hline KACC 11889 & USA & (Yabuuchi et al., 1992) \\
\hline KTCT 12374 & South Korea & (Lee et al., 2005) \\
\hline \multicolumn{3}{|l|}{ Other Burkholderia spp. } \\
\hline cepacia KACC 10189 & USA & (Nzula et al., 2000) \\
\hline cepacia KACC 10190 & Trinidad & (Stanier et al., 1966) \\
\hline cepacia KACC 10337 & USA & (Zaid et al., 2012) \\
\hline cepacia KACC 12679 & South Korea & NAS \\
\hline cepacia $\mathrm{KACC} 15010$ & South Korea & NAS \\
\hline kururiensis KACC 12038 & Japan & (Zhang et al., 2000) \\
\hline sp. KJ006 & South Korea & (Cho et al., 2007) \\
\hline megalochromosomata KACC 17925 & South Korea & (Baek et al., 2015) \\
\hline phymatum KACC 12032 & South Korea & NAS \\
\hline phytofirmans KACC 12042 & Netherland & (Sessitsch et al., 2005) \\
\hline pyrrocinia KACC 17914 & South Korea & (Lee et al., 2011) \\
\hline stabilis KACC 12028 & Belgium & (Vandamme et al., 2000) \\
\hline
\end{tabular}

NAS, National Institute of Agricultural Science, South Korea; KACC, Korean Agricultural Culture Collection; KCTC, Korean Collection of Type Cultures 
of the 16S rRNA gene makes it insufficient as a molecular marker to reveal the intrageneric differences among closely related species (Maeda et al., 2006). Hence, novel molecular markers capable of discriminating between taxonomically related species are needed.

The availability of the whole genome sequences of several strains of bacterial pathogens paved the way for improvements of the molecular applications including more accurate molecular detection (Tao et al., 2015). Previous studies have shown that gene probing from comparative genomic analysis is an efficient method for providing target-specific molecular markers by selection of the most appropriate species-specific sequences (Baek et al., 2018; Papaiakovou et al., 2017). Therefore, the objective of this study was to generate highly sensitive and species-specific primer pairs, using genomics-based analysis, for rapid simultaneous molecular detection of B. glumae and B. gladioli, particularly in rice seeds.

\section{Materials and Methods}

Bacterial strains and culture conditions. Bacterial strains used in this study were obtained from the Korean Agricultural Culture Collection (KACC) and the Korean Collection of Type Cultures (KCTC) (Table 1). Strains were streaked on Luria-Bertani (LB) agar and incubated for 2 days at $30^{\circ} \mathrm{C}$. After confirmation of pure cultures, single colonies were transferred to fresh LB broth and incubated in a shaking incubator at $200 \mathrm{rpm}$ at $30^{\circ} \mathrm{C}$. The bacterial concentration was determined at an optical density of 600 $\mathrm{nm}\left(\mathrm{OD}_{600}\right)$ and viable cells were enumerated using a standard plate-counting procedure on LB agar.

Comparative genomic analysis and primer design to screen species-specific gene sequences. B. glumae and $B$. gladioli species-specific primers were designed to identify unique genes for each species. Genome information of all registered strains in each species (Table 2) were obtained from the National Center for Biotechnology Information (NCBI) database (ftp://ftp.ncbi.nlm.nih.gov/genomes/ bacteria/). Genome sequences of the representative plant pathogens of each species, B. glumae BGR1 and B. gladioli BSR3, were first searched through BLASTN against the reconstructed NCBI non-redundant (nr) DNA sequence database excluding genome sequences of $B$. glumae or $B$. gladioli species, respectively ( $\mathrm{Yu}$ et al., 2010). To eliminate genes highly matched with other bacteria, the coding sequences (CDS) with query coverage and identity $<30 \%$ including non-matched CDSs were selected as putative target genes for B. glumae and B. gladioli species. Subse-
Table 2. Genome sequences of bacterial strain used in this study

\begin{tabular}{|c|c|c|c|}
\hline Strain & Assembly & $\begin{array}{l}\text { Size } \\
(\mathrm{Mb})\end{array}$ & Level \\
\hline \multicolumn{4}{|l|}{ Burkholderia glumae } \\
\hline BGR1 & GCA_000022645.2 & 7.28 & Complete \\
\hline PG1 & GCA_000835205.1 & 7.90 & Complete \\
\hline ATCC 33617 & GCA_000960995.1 & 6.82 & Complete \\
\hline AU6208 & GCA_000300395.2 & 6.06 & Contig \\
\hline $3252-8$ & GCA_000365245.1 & 6.12 & Contig \\
\hline NCPPB 3923 & GCA_000801065.1 & 6.66 & Contig \\
\hline FDAARGOS_346 & GCA_002206305.2 & 6.87 & Contig \\
\hline LMG 2196 & GCA_000300755.1 & 5.77 & Contig \\
\hline $336 g r-1$ & GCA_000503955.1 & 6.51 & Contig \\
\hline \multicolumn{4}{|l|}{ Burkholderia gladioli } \\
\hline ATCC 10248 & GCA_000959725.1 & 8.90 & Complete \\
\hline BSR3 & GCA_000194745.1 & 9.05 & Complete \\
\hline KACC 11889 & GCA_002208175.1 & 8.85 & Complete \\
\hline FDAARGOS_389 & GCA_002393425.1 & 8.29 & Complete \\
\hline ATCC 25417 & GCA_000756855.1 & 9.31 & Scaffold \\
\hline $\begin{array}{l}\text { UCD-UG_CHA- } \\
\text { PALOTE }\end{array}$ & GCA_000757585.1 & 8.53 & Scaffold \\
\hline SN82F6 & GCA_000981885.1 & 8.46 & Scaffold \\
\hline $3848 s-5$ & GCA_000365265.1 & 7.87 & Contig \\
\hline NBRC 13700 & GCA_000739755.1 & 8.76 & Contig \\
\hline NGJ1 & GCA_001028765.1 & 8.02 & Contig \\
\hline MSMB1756 & GCA_001527485.1 & 8.19 & Contig \\
\hline FDAARGOS_390 & GCA_002554225.1 & 8.81 & Contig \\
\hline FDAARGOS_391 & GCA_002554395.1 & 8.38 & Contig \\
\hline Coa14 & GCA_002917905.1 & 8.46 & Contig \\
\hline
\end{tabular}

quently, MegaBLAST searches were performed using the selected genes as a query against the constructed subject nucleotide sequences consisting of genome sequences of other B. glumae and B. gladioli strains (Table 2) to collect highly homologous genes in all strains belonging to each target species. For successful PCR amplification of the homologous genes, primers were designed using the Primer3 program (Rozen and Skaletsky, 2000). The specificity of the designed primer pairs was predicted by implementing the Primer-BLAST (https://www.ncbi.nlm.nih.gov/tools/ primer-blast) in silico PCR tool of NCBI using the default option.

PCR conditions. PCR was performed using Taq polymerase (TaKaRa Bio, Kusatsushi, Japan). Standard PCR mixtures with a total volume of $50 \mu$ l were prepared with an optimal level of each primer for the monoplex PCR or both primer pairs for the duplex PCR. The PCR was performed using a Sure Cycler 8800 thermal cycler (Agilent Technologies, Santa Clara, CA, USA) using an initial de- 
naturation at $95^{\circ} \mathrm{C}$ for $2 \mathrm{~min}$; followed by 35 cycles of $95^{\circ} \mathrm{C}$ for $30 \mathrm{~s}, 54^{\circ} \mathrm{C}$ for $30 \mathrm{~s}, 72^{\circ} \mathrm{C}$ for $1 \mathrm{~min}$; and a final extension at $72^{\circ} \mathrm{C}$ for $3 \mathrm{~min}$.

All the designed primer pairs (Supplementary Table 1) were tested against five strains of B. glumae (BGR1, 411gr6, 201sh-1, 957856-41-c, and 117g1-7-a) and six strains of B. gladioli (BSR3, KACC 18962, KACC 18963, KACC 13944, KACC 11889, and KTCT 12374). Primer pairs exhibiting efficient detection in PCR were selected for further investigation and for assessment of their sensitivity, specificity, and applicability in duplex PCR.

Specificity and sensitivity of detection of $B$. glumae and $B$. gladioli using the designed primers. To evaluate the specificity of the designed primers for detection of $B$. glumae and B. gladioli, PCR was performed using genomic DNA (gDNA) or directly on bacterial cell suspensions of the representative target strains, $B$. glumae BGR1 and $B$. gladioli BSR3, and a related Burkholderia species (Table $1)$. The gDNA was extracted from cultures of the tested strains using the Wizard ${ }^{\circledR}$ Genomic DNA Purification Kit (Promega, Madison, WI, USA), following the manufacturer's instructions. Quality and concentration of the extracted gDNA were assessed using a NanoDrop ND-2000 spectrophotometer (Thermo Fisher Scientific, Waltham, MA, USA). The gDNA concentration for all strains was adjusted to $100 \mathrm{ng} / \mu \mathrm{l}$ for the PCR assays. Cultures from the tested strains, prepared as explained above, were preheated for $8 \mathrm{~min}$ at $95^{\circ} \mathrm{C}$ and were used as a template for the PCR assays after appropriate dilution.

To evaluate the sensitivity and lowest detection limits of the designed primers, both gDNA and bacterial cell suspensions were used for the PCR assays. Briefly, cultures of both strains with the same $\mathrm{OD}_{600}$ values, and $100 \mathrm{ng} / \mu \mathrm{l}$ gDNA of B. glumae BGR1 and B. gladioli BSR3 were 10fold serially diluted nine and six times, respectively. Each dilution was the template for the monoplex and duplex PCR assays, and the detection limits were determined at the gDNA and cellular level.

Separate and simultaneous detection of $B$. glumae and $B$. gladioli on inoculated rice seeds. The designed primer pairs were evaluated for their ability to detect $B$. glumae BGR1 and B. gladioli BSR3 separately or simultaneously on rice seeds. Artificial inoculation of rice seeds and detection of the bacterial pathogens were as previously described (Baek et al., 2018) with slight modifications. Briefly, rice seeds were surface-sterilized by immersion in $70 \%$ ethanol for $30 \mathrm{~min}$ and subsequently in 1\% sodium hypochlorite solution for $10 \mathrm{~min}$, extensively washed five times with sterile distilled water, then completely dried aseptically. Bacterial inocula were formulated from cultures of $B$. glumae BGR1 and B. gladioli BGR3 prepared as explained above. Bacterial cells were harvested by centrifugation at $7000 \mathrm{~g}$ for $5 \mathrm{~min}$ and washed twice and resuspended in sterile water. The suspensions were serially diluted after adjustment of $\mathrm{OD}_{600}$ values, and $5 \mathrm{~g}$ of surface-sterilized rice seeds were inoculated by immersion in $15 \mathrm{ml}$ of the prepared suspension of each strain and of a 1:1 mix of both strains. Inoculated rice seeds were then incubated at $30^{\circ} \mathrm{C}$ in a shaking incubator at $100 \mathrm{rpm}$ for $1 \mathrm{~h}$. Following incubation, bacterial suspensions were removed, and seeds were dried on a clean bench. After drying, bacteria from rice seeds were collected using $15 \mathrm{ml}$ sterile distilled water containing $0.03 \%$ Tween 20 by shaking at $180 \mathrm{rpm}$ for 20 min. The collected suspensions were used for PCR assays and for assessment of the bacterial population by the standard plate-counting procedure.

\section{Results}

Selection of efficient primers for detection of $B$. glumae and $\boldsymbol{B}$. gladioldi. Among the designed primers (Supplementary Table 1), Bglu3 and Bgla9 were selected for
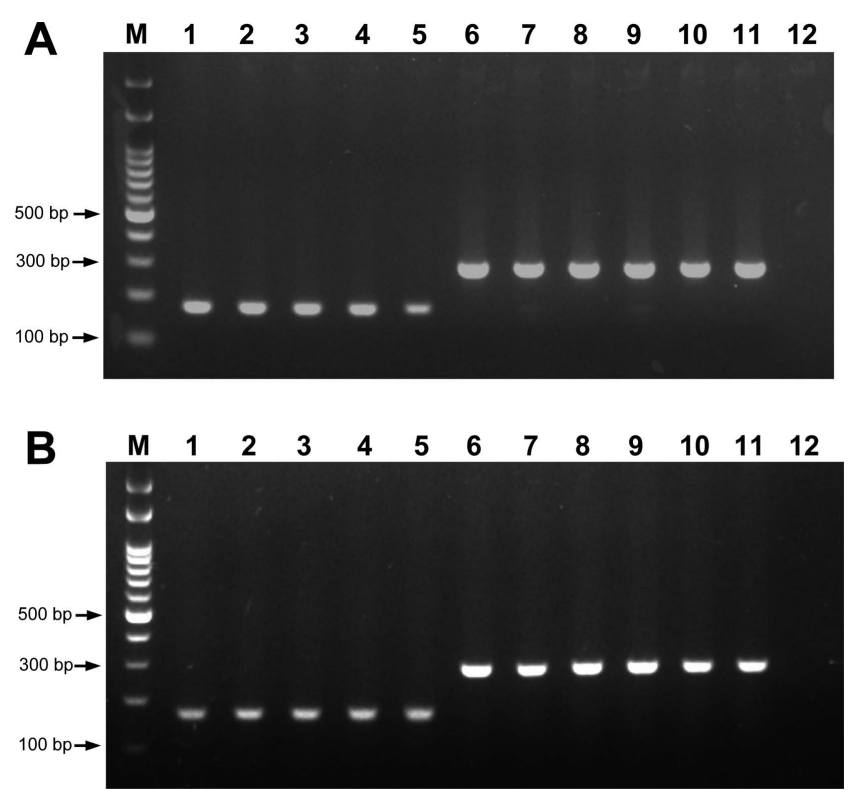

Fig. 1. Amplification of the expected PCR products (A) Products from bacterial genomic DNA. (B) Products from suspensions of five strains of Burkholderia glumae (Lane 1-5) amplified using Bglu3-f and Bglu3-r primers and six strains of Burkholderia gladioli (Lane 6-11) amplified using Bgla9-f and Bgla9-r primers. Lane 12 is a negative control. Specific bands were clearly visible on the $2 \%$ agarose gel at $174 \mathrm{bp}$ for $B$. glumae and $289 \mathrm{bp}$ for $B$. gladioli. M denotes the $1 \mathrm{~kb}$ DNA ladder. 


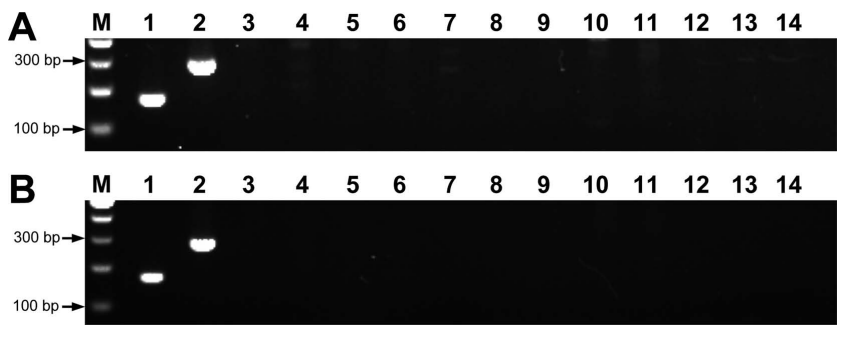

Fig. 2. Specificity assay for the designed primer pairs (Bglu3 and Bgla9), by amplification of the expected PCR products (A) Products from bacterial genomic DNA. (B) Products from cell suspensions. Lane 1, Burkholderia glumae BGR1; lane 2, B. gladioli BSR3; lane 3, B. cepacia KACC 10189; lane 4, B. cepacia KACC 10190; lane 5, B. cepacia KACC 10337; lane 6, B. cepacia KACC 12679; lane 7, B. cepacia KACC 15010; lane 8, B. kururiensis KACC 12038; lane 9, Burkholderia sp. KJ006; lane 10, B. megalochromosomata KACC 17925; lane 11, B. phymatum KACC 12032; lane 12, B. phytofirmans KACC 12042; lane 13, B. pyrrocinia KACC 17914; lane 14, B. stabilis KACC 12028. Specific bands were clearly visible on the $2 \%$ agarose gel at $174 \mathrm{bp}$ for B. glumae BGR1 and $289 \mathrm{bp}$ for B. gladioli BSR3. No bands were observed with the other tested Burkholderia species. $\mathrm{M}$ denotes the $1 \mathrm{~kb}$ DNA ladder.

detection of $B$. glumae and B. gladioli, respectively. PCR assay using both primer pairs resulted in specific bands that were clearly visible at $174 \mathrm{bp}$ with the five tested $B$. glumae strains and at $289 \mathrm{bp}$ with the six tested B. gladioli strains using bacterial gDNA or directly from preheated bacterial cell suspensions (Fig. 1A, B). The specificity of the selected primer pairs was confirmed by testing against other related species of Burkholderia. As shown in Fig. 2A, $\mathrm{B}$, no bands were observed with other Burkholderia spp. at the expected product size. However, specific bands were exclusively observed with $B$. glumae BGR1 and B. gladioli BSR3, using bacterial gDNA or cell suspensions.

Sensitivity and lowest detection limits of the selected primer pairs. Different dilutions of $B$. glumae BGR1 and B. gladioli BSR3 gDNA were used for monoplex and duplex PCR assays. Specific bands were clearly visible on the agarose gel at $174 \mathrm{bp}$ for $B$. glumae and $289 \mathrm{bp}$ for $B$. gladioli up to $0.1 \mathrm{ng}$ gDNA template in both monoplex PCR assays (Fig. 3A, B) and in the duplex PCR using both primer pairs (Fig. 3C). When different dilutions of bacterial suspensions were used for monoplex and duplex PCR assays, specific bands were also clearly visible at $174 \mathrm{bp}$ for $B$. glumae BGR1 and 289 bp for B. gladioli BSR3 up to the $10^{-3}$ dilution, which was equivalent to $3.86 \times 10^{2}$ cells per PCR mixture for B. glumae and $5.85 \times 10^{2}$ cells per PCR mixture for B. gladioli.
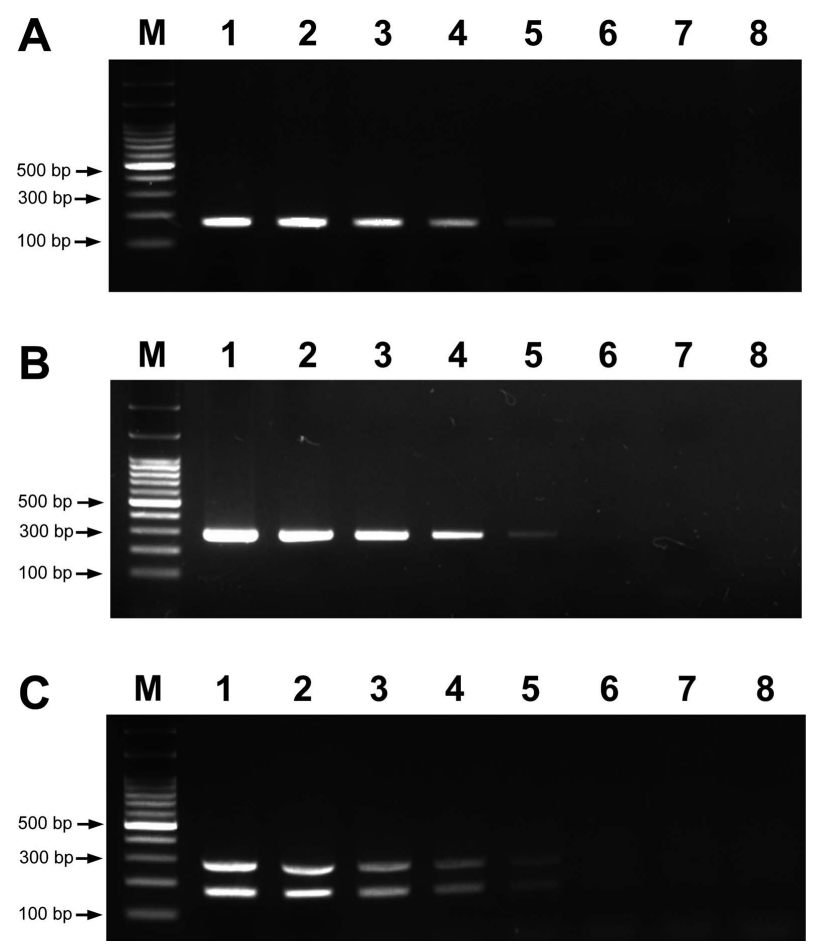

Fig. 3. Sensitivity assay for the designed primer pairs (Bglu3 and Bgla9), by amplification of the expected PCR product from genomic DNA (gDNA) from (A) Burkholderia glumae BGR1, (B) B. gladioli BSR3 and (C) mixed sample (1:1) of B. glumae BGR1 and B. gladioli BSR3 in a duplex PCR assay Lane 1, 100 ng gDNA; lane 2, 10 ng gDNA; lane 3, 1 ng gDNA; lane 4, 0.1 ng gDNA; lane 5, 0.01 ng gDNA, lane 6, 1 pg gDNA, lane 7, 0.1 pg; lane 8 , no gDNA template. Specific bands were clearly visible on the $2 \%$ agarose gel at $174 \mathrm{bp}$ for B. glumae and $289 \mathrm{bp}$ for B. gladioli up to the $0.1 \mathrm{ng}$ gDNA template. M denotes the $1 \mathrm{~kb}$ DNA ladder.

Sensitivity and lowest detection limits of selected primer pairs for inoculated rice seeds. From the harvested suspensions of the inoculated rice seeds, specific bands were clearly observed on agarose gels from the monoplex and duplex PCR assays at 174 bp for B. glumae and 289 bp for $B$. gladioli up to the $10^{-2}$ dilution (Fig. 5). The detection limit of bacteria on rice seeds determined by assessment of the bacterial populations in the seed suspensions was equivalent to $1.86 \times 10^{3}$ cells per rice seed for $B$. glumae BGR1 and $1.04 \times 10^{4}$ cells per rice seed of $B$. gladioli BSR3.

\section{Discussion}

Molecular detection of plant pathogens using traditional PCR assays efficiently supports decision making and provides critical information for disease management. 

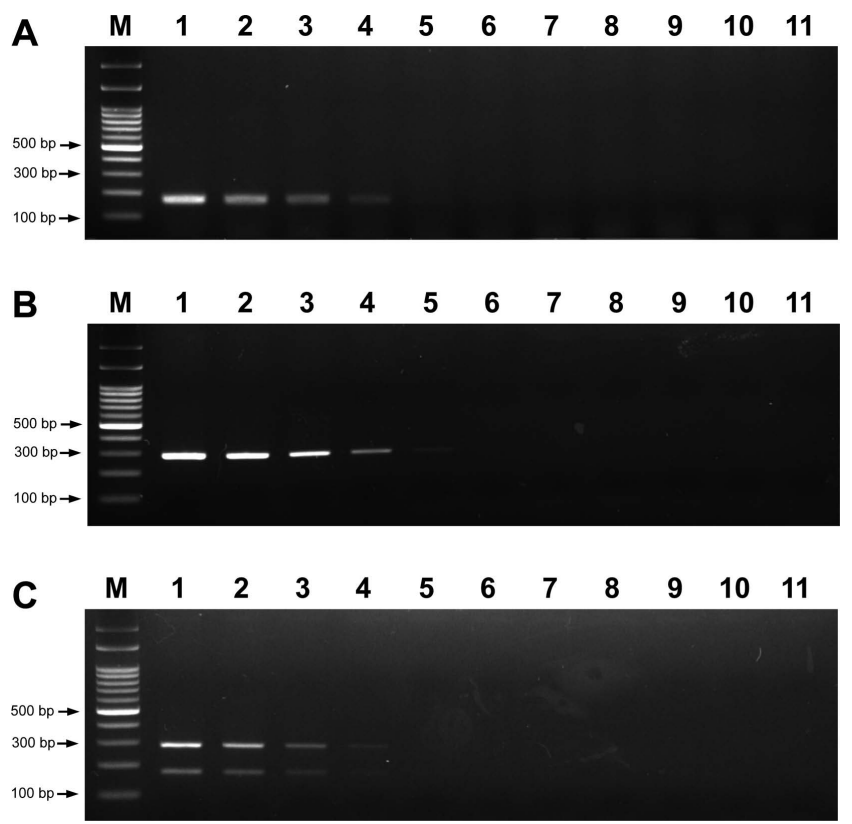

Fig. 4. Sensitivity assay for the designed primer pairs (Bglu3 and Bgla9), by amplification of the expected PCR product from bacterial cell suspensions of (A) Burkholderia glumae BGR1, (B) Burkholderia gladioli BSR3 and (C) mixed sample of B. glumae BGR1 and B. gladioli BSR3 in the multiplex PCR assay Lane 1 , Overnight cultures; lane $2-10$, serially diluted cultures $\left(10^{-1}\right.$ to $\left.10^{-9}\right)$; lane 11 , no cells. Clear specific bands were visible on the $2 \%$ agarose gel at $174 \mathrm{bp}$ for $B$. glumae BGR1 and $289 \mathrm{bp}$ for $B$. gladioli BSR3 up to the $10^{-3}$ dilution (approximately 300 cells for B. glumae and approximately 500 cells for B. gladioli). M denotes the $1 \mathrm{~kb}$ DNA ladder.
Therefore, research has aimed at improving the specificity and sensitivity of detection of plant pathogens. With the recent availability of genome sequences of several strains of bacterial pathogens, the comparative genomics approach has proven useful for screening and identifying novel specific molecular targets to facilitate the accurate and highly specific detection of several bacterial species (Baek et al., 2018; Papaiakovou et al., 2017; Tao et al., 2015). In this study, novel primer pairs targeting unique and conserved loci generated by comparative genomics sensitively and specifically detected two major bacterial pathogens of rice, B. glumae and B. gladioli. Among the designed primers, two pairs were selected for further investigation based on their efficiency and applicability in duplex PCR assay. Both selected primer pairs (Bglu3 and Bgla9) amplified the expected PCR products using gDNA or preheated cell suspensions from target pathogens, but not from other related Burkholderia species, confirming their species specificity.

The detection limits of the novel primers observed in this study were relatively lower than previously developed primers, particularly in the duplex PCR for simultaneous detection of both pathogens (Cui et al., 2016; Furuya et al., 2002; Maeda et al., 2006). This is mainly due to the comparative genomics approach for the primer design we adopted. Maeda et al. (2006) developed molecular markers for detection of B. glumae, B. gladioli, and B. plantarii using gyrB sequences in multiplex PCR. However, the amplicon size similarity of the PCR product particularly in B. glumae (529 bp) and B. gladioli (479 bp) makes it dif-

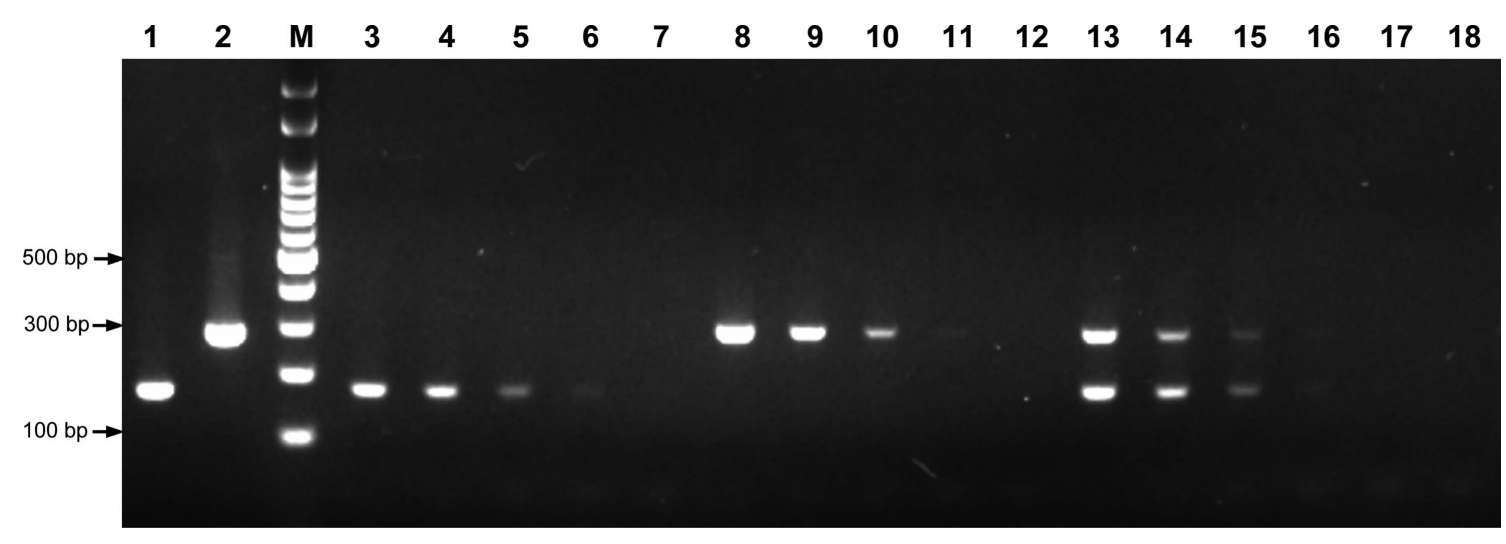

Fig. 5. Sensitivity assay for the designed primer pairs (Bglu3 and Bgla9), by amplification of the expected PCR product from rice seeds inoculated with different dilutions of Burkholderia glumae BGR1, Burkholderia gladioli BSR3 and mixed co-inoculation Suspensions from rice seeds inoculated with different dilutions of the tested strains or their mix were collected using sterile distilled water containing $0.03 \%$ Tween 20 and used as templates for the PCR. Lane 1, $100 \mathrm{ng}$ gDNA from B. glumae BGR1; lane 2, $100 \mathrm{ng}$ gDNA from B. gladioli BSR3; lane 3, cell suspension of overnight culture from $B$. glumae; lane, 4-7, $10^{-1}$ to $10^{-4}$ dilutions; lane 8 , cell suspension of overnight culture from $B$. gladioli; lane 9-12, $10^{-1}$ to $10^{-4}$ dilutions; lane 13, 1:1 cell suspension mix from overnight culture from $B$. glumae and $B$. gladioli; lane $14-17,10^{-1}$ to $10^{-4}$ dilutions. M, $1 \mathrm{~kb}$ DNA ladder; lane 18, un-inoculated surface sterilized rice seeds as a negative control. 
ficult for the rapid differentiation of both species without the need for sequencing confirmation of the PCR products. In the current study, the amplicon sizes using the selected primer pairs were $174 \mathrm{bp}$ for B. glumae BGR1 and $289 \mathrm{bp}$. These sizes allowed the differentiation between both species in the same duplex PCR assay. Although both selected primers exhibited similar sensitivity, the Bgla9 primer pair for $B$. gladioli was apparently markedly more sensitive than the Bglu3 primer pair for B. glumae, particularly when the bacterial suspensions were used as templates for PCR. PCR using the Bgla9 primer pair resulted in a more clearly visible band at the detection limit and a band was weakly visible beyond the assigned detection limit.

One of the most important disease management practices is the use of pathogen-free seeds. Particular attention to seed-borne pathogens, such as B. glumae and B. gladioli, has been suggested (Cottyn et al., 2009). The novel primers designed in this study accurately detected relatively low numbers of $B$. glumae and $B$. gladioli in a single duplex PCR assay of rice seeds. Therefore, detection of $B$. glumae and $B$. gladioli from rice seeds using the designed primers might be rapid and accurate without the need for isolation of the bacteria. Although the designed primers were tested on the available strains of B. glumae and B. gladioli from USA and South Korea, they are expected to detect any other strains of the target species, since they were designed on all the registered genome sequences from different strains of both species. Strains used from primer designed (9 strains of B. glumae and 14 strains of B. gladioli) were originally isolated from different geographical locations including Germany, Japan, USA, South Korea and Colombia.

Further investigations should consider other factors that might be involved in the applicability of these primers in naturally contaminated rice seeds. These factors include primer efficiency in the presence of other DNA sources of plants or other natural contaminants on the rice seeds.

The collective data of this study confirm the efficiency of the comparative genomics approach in screening for unique molecular targets in the development of sensitive diagnostic primers for two important bacterial pathogens of rice. The novel primers designed in this study could be a more sensitive detection tool that might facilitate the dissemination of pathogen-free rice seeds. The primers might prove valuable in quarantine facilities for improving the detection efficiency of both bacterial species.

\section{Acknowledgments}

We thank Prof. Jong Hyun Ham of Louisiana State Uni- versity for providing genomic DNAs of B. glumae strains. This work was supported by Basic Science Research Program through the National Research Foundation of Korea (NRF) funded by the Ministry of Education (2016R1D1A1B03930678), and by grants from the Strategic Initiative for Microbiomes in Agriculture and Food, Ministry of Agriculture, Food and Rural Affairs, Republic of Korea (No. 916009021SB010).

\section{References}

Awika, J. M. 2011. Major cereal grains production and use around the world. In: Advances in cereal science: Implications to food processing and health promotion, eds. by J. M. Awika, V. Piironen and S. Bean, pp. 1-13. American Chemical Society, Washington, D. C., USA.

Baek, I., Seo, B., Lee, I., Lee, K., Park, S. C., Yi, H. and Chun, J. 2015. Burkholderia megalochromosomata sp. nov., isolated from grassland soil. Int. J. Syst. Evol. Microbiol. 65:959-964.

Baek, K. Y., Lee, H. H., Son, G. J., Lee, P. A., Roy, N., Seo, Y. S. and Lee, S. W. 2018. Specific and sensitive primers developed by comparative genomics to detect bacterial pathogens in grains. Plant Pathol. J. 34:104-112.

Cho, H. S., Park, S. Y., Ryu, C. M., Kim, J. F., Kim, J. G. and Park, S. H. 2007. Interference of quorum sensing and virulence of the rice pathogen Burkholderia glumae by an engineered endophytic bacterium. FEMS Microbiol. Ecol. 60:1423.

Cottyn, B., Van Outryve, M. F., Cerez, M. T., De Cleene, M., Swings, J. and Mew, T. W. 1996. Bacterial disease of rice. II. Characterization of pathogenic bacteria associated with sheath rot complex and grain discoloration of rice in the Philippines. Plant Dis. 80:438-445.

Cottyn, B., Regalado, E., Lanoot, B., De Cleene, M., Mew, T. W. and Swings, J. 2001. Bacterial populations associated with rice seed in the tropical environment. Phytopathology 91:282292.

Cottyn, B., Debode, J., Regalado, E., Mew, T. W. and Swings, J. 2009. Phenotypic and genetic diversity of rice seed-associated bacteria and their role in pathogenicity and biological control. J. Appl. Microbiol. 107:885-897.

Cui, Z., Ojaghian, M. R., Tao, Z., Kakar, K. U., Zeng, J., Zhao, W., Duan, Y., Vera Cruz, C. M., Li, B., Zhu, B. and Xie, G. 2016. Multiplex PCR assay for simultaneous detection of six major bacterial pathogens of rice. J. Appl. Microbiol. 120:13571367.

FAO. Feeding the world, eradicating hunger: executive summary. World summit on food security 2009. FAO Database. Version: 2009. URL http://www.fao.org/fileadmin/templates/ wsfs/Summit/WSFS_Issues_papers/WSFS_Background_ paper_Feeding_the_world.pdf [20 July 2018].

Furuya, N., Ura, H., Iiyama, K., Matsumoto, M., Takeshita, M. and Takanami, Y. 2002. Specific oligonucleotide primers 
based on sequences of the 16S-23S rDNA spacer region for the detection of Burkholderia gladioli by PCR. J. Gen. Plant Pathol. 68:220-224.

Goto, K. and Ohata, K. 1956. New bacterial diseases of rice (brown stripe and grain rot). Ann. Phytopathol. Soc. Jpn. 21:46-47.

Ham, J. H., Melanson, R. A. and Rush, M. C. 2011. Burkholderia glumae: next major pathogen of rice?. Mol. Plant Pathol. 12:329-339.

Hikichi, Y., Okuno, T. and Furusawa, I. 1993. Immunofluorescent antibody technique for detecting Pseudomonas glumae on rice plants. Ann. Phytopathol. Soc. Jpn. 59:477-480.

Jeong, Y., Kim, J., Kim, S., Kang, Y., Nagamatsu, T. and Hwang, I. 2003. Toxoflavin produced by Burkholderia glumae causing rice grain rot is responsible for inducing bacterial wilt in many field crops. Plant Dis. 87:890-895.

Jung, B., Park, J., Kim, N., Li, T., Kim, S., Bartley, L. E., Kim, J., Kim, I., Kang, Y., Yun, K., Choi, Y., Lee, H., Ji, S., Lee, K., Kim, B., Shon, J., Kim, W., Liu, K., Yoon, D., Kim, S., Seo, Y. and Lee, J. 2018. Cooperative interactions between seedborne bacterial and air-borne fungal pathogens on rice. Nat. Commun. 9:31.

Kawanishi, T., Shiraishi, T., Okano Y., Sugawara, K., Hashimoto, M., Maejima, K., Komatsu, K., Kakizawa, S., Yamaji, Y., Hamamoto, H., Oshima, K. and Namba, S. 2011. New detection systems of bacteria using highly selective media designed by SMART: Selective Medium-Design Algorithm Restricted by Two Constraints. PLoS One 6:e16512.

Kawaradani, M., Okada, K. and Kusakari, S. 2000. New selective medium for isolation of Burkholderia glumae from rice seeds. J. Gen. Plant Pathol. 66:234-237.

Lee, C. J., Lee, J. T., Kwon, J. H., Kim, B. C. and Park, W. 2005. Occurrence of bacterial soft rot of onion plants caused by Burkholderia gladioli pv. alliicola in Korea. Aust. Plant Pathol. 34:287-292.

Lee, C. J., Yun, H. S., Jhune, C. S., Cheong, J. C. and Yoo, Y. B. 2010. Occurrence of bacterial soft rot of Pleurotus ostreatus caused by Burkholderia gladioli pv. agaricicola in Korea. J. Plant Pathol. 92:235-240.

Lee, K. Y., Kong, H. G., Choi, K. H., Lee, S. W. and Moon, B. J. 2011. Isolation and identification of Burkholderia pyrrocinia CH-67 to control tomato leaf mold and damping-off on crisphead lettuce and tomato. Plant Pathol. J. 27:59-67.

Maeda, Y., Shinohara, H., Kiba, A., Ohnishi, K., Furuya, N., Kawamura, Y., Ezaki, T., Vandamme, P., Tsushima, S. and Hikichi, Y. 2006. Phylogenetic study and multiplex PCR-based detection of Burkholderia plantarii, Burkholderia glumae and Burkholderia gladioli using gyrB and rpoD sequences. Int. J. Syst. Evol. Microbiol. 56:1031-1038.

Nandakumar, R., Bollich, P. A., Shahjahan, A. K. M., Groth, D. E. and Rush, M. C. 2008. Evidence for the soilborne nature of the rice sheath rot and panicle blight pathogen, Burkholderia gladioli ${ }_{1}$. Can. J. Plant Pathol. 30:148-154.

Nandakumar, R., Shahjahan, A. K. M., Yuan, X. L., Dickstein, E.
R., Groth, D. E, Clark, C. A., Cartwright, R. D. and Rush, M. C. 2009. Burkholderia glumae and B. gladioli cause bacterial panicle blight in rice in the southern United States. Plant Dis. 93:896-905.

Nzula, S., Vandamme, P. and Govan, J. R. 2000. Sensitivity of the Burkholderia cepacia complex and Pseudomonas aeruginosa to transducing bacteriophages. FEMS Immunol. Med. Microbiol. 28:307-312.

Papaiakovou, M., Pilotte, N., Grant, J. R., Traub, R. J., Llewellyn, S., McCarthy, J. S., Krolewiecki, A. J., Cimino, R., Mejia, R. and Williams, S. A. 2017. A novel, species-specific, real-time PCR assay for the detection of the emerging zoonotic parasite Ancylostoma ceylanicum in human stool. PLoS Negl. Trop. Dis. 11:e0005734.

Rozen, S. and Skaletsky, H. 2000. Primer3 on the WWW for general users and for biologist programmers. Methods Mol. Biol. 132:365-386.

Salles, J. F., De Souza, F. A. and van Elsas, J. D. 2002. Molecular method to assess the diversity of Burkholderia species in environmental samples. Appl. Environ. Microbiol. 68:15951603.

Seo, Y. S., Lim, J., Choi, B. S., Kim, H., Goo, E., Lee, B., Lim, J. S., Choi, I. Y., Moon, J. S., Kim, J. and Hwang, I. 2011. Complete genome sequence of Burkholderia gladioli BSR3. J. Bacteriol. 193:3149.

Sessitsch, A., Coenye, T., Sturz, A. V., Vandamme, P., Barka, E. A., Salles, J. F., Van Elsas, J. D., Faure, D., Reiter, B., Glick, B. R., Wang-Pruski, G. and Nowak, J. 2005. Burkholderia phytofirmans sp. nov., a novel plant-associated bacterium with plantbeneficial properties. Int. J. Syst. Evol. Microbiol. 55:11871192.

Stackebrandt, E. and Goebel, B. M. 1994. Taxonomic note: a place for DNA-DNA reassociation and 16S rRNA sequence analysis in the present species definition in bacteriology. Int. J. Syst. Bacteriol. 44:846-849.

Stanier, R. Y., Palleroni, N. J. and Doudoroff, M. 1966. The aerobic pseudomonads: a taxonomic study. J. Gen. Microbiol. 43:159-271.

Takeuchi, T., Sawada, H., Suzuki, F. and Matsuda, I. 1997. Specific detection of Burkholderia plantarii and B. glumae. Jpn. J. Phytopathol. 63:455-462.

Tao, T., Chen, Q., Bie, X., Lu, F. and Lu, Z. 2015. Mining of novel species-specific primers for PCR detection of Listeria monocytogenes based on genomic approach. World J. Microbiol. Biotechnol. 31:1955-1966.

Trung, H. M., Van, N. V., Vien, N. V., Lam, D. T. and Lien, M. 1993. Occurrence of rice grain rot disease in Vietnam. Int. Rice Res. Notes 18:30.

Tsushima, S., Wakimoto, S. and Mogi, S. 1986. Selective medium for detecting Pseudomonas glumae Jurita et Tabei, the causal bacterium of grain rot of rice. Ann. Phytopathol. Soc. Jpn. 52:253-259.

Ura, H., Furuya, N., Iiyama, K., Hidaka, M., Tsuchiya, K. and Matsuyama, N. 2006. Burkholderia gladioli associated with 
symptoms of bacterial grain rot and leaf-sheath browning of rice plants. J. Gen. Plant Pathol. 72:98-103.

Vandamme, P., Mahenthiralingam, E., Holmes, B., Coenye, T., Hoste, B., De Vos, P., Henry, D. and Speert, D. P. 2000. Identification and population structure of Burkholderia stabilis sp. nov. (formerly Burkholderia cepacia genomovar IV). J. Clin. Microbiol. 38:1042-1047.

Yabuuchi, E., Kosako, Y., Oyaizu, H., Yano, I., Hotta, H., Hashimoto, Y., Ezaki, T. and Arakawa, M. 1992. Proposal of Burkholderia gen. nov. and transfer of seven species of the genus Pseudomonas homology group II to the new genus, with the type species Burkholderia cepacia (Palleroni and Holmes 1981) comb. nov. Microbiol. Immunol. 36:1251-1275.
Yu, S., Chen, W., Wang, D., He, X., Zhu, X. and Shi, X. 2010. Species-specific PCR detection of the food-borne pathogen Vibrio parahaemolyticus using the $\operatorname{irg} B$ gene identified by comparative genomic analysis. FEMS Microbiol. Lett. 307:65-71.

Zaid, A. M., Bonasera, J. M. and Beer, S. V. 2012. OEM-A new medium for rapid isolation of onion-pathogenic and onionassociated bacteria. J. Microbiol. Methods 91:520-526.

Zhang, H., Hanada, S., Shigematsu, T., Shibuya, K., Kamagata, Y., Kanagawa, T. and Kurane, R. 2000. Burkholderia kururiensis sp. nov., a trichloroethylene (TCE)-degrading bacterium isolated from an aquifer polluted with TCE. Int. J. Syst. Evol. Microbiol. 50:743-749. 